\title{
Toxic maculopathy due to antimalarial drugs
}

INSERM

\section{Source}

INSERM. (1999). Orphanet: an online rare disease and orphan drug data base. Toxic maculopathy due to antimalarial drugs. ORPHA:279894

Toxic maculopathy due to antimalarial drugs is a rare, acquired eye disease, due to longterm exposure to chloroquinine (CQ) or hydrochloroquinine (HCQ), characterized by a slowly progressive, usually non-reversible, development of bilateral atrophic bull's-eye maculopathy (progressive loss of central vision acuity, reduced color vision and central scotoma), which in severe cases can spread over the entire fundus, leading to widespread retinal atrophy and visual loss. 